\title{
Effectiveness of the Fitness Program «WAY TO A HEALTHY LIFE»
}

\author{
Maryna Khmara ${ }^{1}$, Oleksandr Mozolev ${ }^{1, *}$, Inna Yashchuk², Oleksandr Alieksieiev ${ }^{3}$, Vasil Kravchuk $^{4}$, \\ Yuriy Dolynniy $^{5}$, Ihor Tomkiv ${ }^{6}$, Oleksandr Binkovskyi ${ }^{6}$, Vasyl Prontenko ${ }^{7}$

\begin{abstract}
${ }^{1}$ Department of Tourism, Theory and Methods of Physical Culture and Valeology of Khmelnytskyi Humanitarian-Pedagogical Academy, Ukraine

${ }^{2}$ Department of Pedagogy, Khmelnytskyi Humanitarian-Pedagogical Academy, Khmelnytskyi, Ukraine ${ }^{3}$ Department of Sport and Sport Games, Kamianets-Podilskyi National Ivan Ohiienko, Ukraine

${ }^{4}$ Department of Logistics, Bohdan Khmelnytsky National Academy of the State Border Guard Service of Ukraine, Khmelnytsky, Ukraine

${ }^{5}$ Department of Physical Education and Sports, Donbas State Machine-Building Academy Kramatorsk, Ukraine Ukraine, Khmelnytskyi, Ukraine

${ }^{7}$ Department of Physical Education, Special Physical Training and Sport, S. P. Koroliov Zhytomyr Military Institute, Zhytomyr,
\end{abstract} \\ ${ }^{6}$ Department of Managerial Personnel Training of the Bohdan Khmelnytskyi National Academy of the State Border Guard Service of
} Ukraine

Received April 30, 2021; Revised June 4, 2021; Accepted July 19, 2021

\section{Cite This Paper in the following Citation Styles}

(a): [1] Maryna Khmara, Oleksandr Mozolev, Inna Yashchuk, Oleksandr Alieksieiev, Vasil Kravchuk, Yuriy Dolynniy, Ihor Tomkiv, Oleksandr Binkovskyi, Vasyl Prontenko , "Effectiveness of the Fitness Program «WAY TO A HEALTHY LIFE»," International Journal of Human Movement and Sports Sciences, Vol. 9, No. 5, pp. 833 - 840, 2021. DOI: 10.13189/saj.2021.090501.

(b): Maryna Khmara, Oleksandr Mozolev, Inna Yashchuk, Oleksandr Alieksieiev, Vasil Kravchuk, Yuriy Dolynniy, Ihor Tomkiv, Oleksandr Binkovskyi, Vasyl Prontenko (2021). Effectiveness of the Fitness Program «WAY TO A HEALTHY LIFE». International Journal of Human Movement and Sports Sciences, 9(5), 833 - 840. DOI: 10.13189/saj.2021.090501.

Copyright $\odot 2021$ by authors, all rights reserved. Authors agree that this article remains permanently open access under the terms of the Creative Commons Attribution License 4.0 International License

\begin{abstract}
The article analyzes the results of testing the effectiveness of the author's fitness program "WAY TO A HEALTHY LIFE" and identifies its impact on physical and morphofunctional indicators of student development during quarantine restrictions. The study involved 149 students aged 17-19 of Khmelnytskyi of Humanitarian-Pedagogical Academy. Methods: Analysis of scientific and methodological sources, pedagogical modeling, pedagogical experiment, pedagogical observation, methods of functional state research (Ruffier test, Stange, Genchi, Yarotskyi, Recovery time after 20 squats), methods of physical condition research (running on the spot for 10 seconds; squats for 30 seconds, hyperextension, twisting the log scale $(\mathrm{cm})$, lifting the torso to the buttocks from a supine position behind the head for 30 seconds, maintaining the position of the stop lying on the forearm, maintaining balance while standing on one leg with arms outstretched), methods of mathematical statistics. Results: The students of the experimental group improved
\end{abstract}

their functional indicators of the development of the cardiovascular, respiratory systems and vestibular stability. The increase was: the Stange test $+7.3 \pm 0.5(\mathrm{~s})(\mathrm{p}<0.001)$ girls, $+9.2 \pm 0.4(\mathrm{~s})(\mathrm{p}<0.001)$ boys; Genchi test $+4.6 \pm$ $0.5(\mathrm{~s})(\mathrm{p}<0.01)$ girls, $+5.4 \pm 0.7(\mathrm{~s})(\mathrm{p}<0.01)$ boys; Yarotskyi test $+7.5 \pm 0.4(\mathrm{~s})(\mathrm{p}<0.001)$ girls, $+7.9 \pm 0.7(\mathrm{~s})$ ( $p<0.001)$ boys; recovery time after exercise improved $-8.5 \pm 2.5(\mathrm{~s})(\mathrm{p}<0.01)$ girls and $-7.5 \pm 1.5(\mathrm{~s})(\mathrm{p}<0.01)$ boys. The developed program contributed to the development of flexibility, improvement of speed-power and coordination abilities of students. Conclusions: Analysis of the dynamics of indicators of morphofunctional and physical condition of students shows the effectiveness of the program "WAY TO A HEALTHY LIFE".

Keywords Fitness Program, Online Platforms, Morphofunctional Indicators, Indicators of Physical Development, Students 


\section{Introduction}

Physical activity is one of the main factors determining the level of physical health of young people. Regular physical activity has a positive effect on the state of the whole organism - promotes mental and physical health, forms vital motor skills, abilities and physical qualities, health culture, increases interest in motor activities and is a mandatory component of full value development of a person [1-2].

The researches conducted during the quarantine restrictions on the organization of the process of physical education indicate changes in the usual way of life, reduced physical activity, changes in the development of motor skills and health of young people [3].

The vast majority of students do not consider physical education during the pandemic and distance learning as a necessary part of their lives. They do not understand that physical education acts as a means of relaxation, rehabilitation and restoration of their vital forces [4]. That is why the educational process on physical education currently has low efficiency.

In order to increase the level of students' interest in physical education, it is necessary to modernize the types of physical activity used in the educational process of higher education institutions. The process of improving the technology of physical education requires the search for new, more rational and interesting forms of physical activity for young people, the introduction of non-traditional means of organizing classes on the basis of developed experimental programs [5-7].

The introduction of the most attractive and relevant for today fitness technologies, which differ significantly from other forms by their efficiency, comprehensive impact on the body, accessibility for all into the system of physical education of students, especially during the pandemic COVID-19, in our opinion, is one of the main and urgent tasks of modernization of traditional technologies of teaching physical culture.

The hypothesis of the research was that the use of modern fitness technologies of the author's program "WAY TO A HEALTHY LIFE" at home will help improve the level of development of physical qualities and morphofunctional indicators of the student body during quarantine restrictions caused by the COVID-19 pandemic.

The development of the author's fitness program "WAY TO A HEALTHY LIFE" was based on the use of the algorithm for making individual fitness programs for independent classes of students [8-9]. During the development of the program, we made the following requirements: the possibility of using the program "WAY TO A HEALTHY LIFE" for students who have outgrown COVID-19;

- the availability and variability of the fitness program;

- the ability to choose the content module of the fitness program in accordance with the individual needs of the student;

- the use of online platforms ZOOM, Google Meet, Viber, Telegram to provide methodological assistance and control;

- the safety of movements in a limited space;

- the possibility of using household items (water bottles, chairs, bed, rugs, etc.) instead of stationary sports equipment.

To study the changes that occurred in students who were engaged in the author's program "WAY TO A HEALTHY LIFE" and the generally accepted method of conducting physical education classes during quarantine restrictions, we monitored the physical and morphofunctional condition of students and compared it with the indices at the initial stage of the research.

The objective of the article is to study the impact of the author's fitness program "WAY TO A HEALTHY LIFE" on the physical and morphofunctional indicators of student development during quarantine restrictions.

To achieve the objective of the study, we needed to solve the following tasks:

1. Development of the program "WAY TO A HEALTHY LIFE" in accordance with the advances requirements (April - May 2020) Tasks: to develop a set of physical exercises to perform at home. The program consists of three content modules:

a) Content module 1. "SUPER ABDOMINAL MUSCLES, SLIM LEGS AND PERFECT BUTTOCK" - includes sets of shaping exercises to strengthen the muscles of the abdomen, leg muscles and buttocks;

b) Content module 2. "STRONG FLEXIBLE BODY" includes sets of exercises for different types of fitness: bodyflex, stretching and Pilates;

c) Content module 3. "STRONG ARMS, ELASTIC CHEST AND STRONG BACK" includes sets of shaping exercises to strengthen the muscles of the arms, chest and back.

2. Approbation of the program on a group of students (June-July 2020). Tasks: to check the possibility of performing exercises at home using the online platforms ZOOM, Google Meet, Viber, Telegram;

3. Making adjustments and refinement of the program (August 2020) Tasks: replacement of some exercises that cause difficulties in the implementation at home);

4. Conducting an experimental study (September-December 2020). Tasks: checking the 
effectiveness of the fitness program "WAY TO A HEALTHY LIFE";

5. Processing of the results of the experimental research (January 2021);

6. Development of recommendations for the implementation of the fitness program "WAY TO A HEALTHY LIFE” (February 2021).

\section{Materials and Methods}

\section{Participants}

The research work was conducted on the basis of Khmelnytskyi Humanitarian-Pedagogical Academy (Ukraine). The subject of the study was 149 students aged 17-19. They were divided into: experimental group (EG) 76 students and control group (CG) - 73 students. The groups were divided according to the requirements of representativeness. The main indicator was the initial level of physical fitness of students, which was determined by a ten-point scale of doing physical exercises for speed, strength, agility and flexibility.

\section{Organization of the Research}

The experimental research to test the effectiveness of the fitness program "WAY TO A HEALTHY LIFE" was conducted for 4 months and included the following stages:

1. Theoretical and formative stage (1-2 weeks). The task of the stage is to form skills of performing fitness program exercises. Classes are of theoretical-explanatory and test-developmental nature.

2. The first training and developmental stage (6-7 weeks). The task of the stage is purposeful physical training of speed, strength, agility, flexibility, development of special skills of independent performance of exercises. Classes are educational-training in nature.

3. Control and corrective stage (1-2 weeks). The task of the stage is to check the effectiveness of the fitness program, make timely adjustments to the program of individual physical development.

4. The second training and developmental stage (5-6 weeks). The task of the stage is purposeful physical training with the use of new motor actions according to the individual needs of students. Classes are educational-training in nature.

5. Control-comparative stage (1-week). The task of the stage is to check the indicators of physical and morphofunctional development of students. Carrying out a comparative analysis of the studied indicators of students of the experimental and control groups.

The training program at the first and the second stages of the research included exercises of mixed type of energy supply, which are aimed at improving coordination of movements, vestibular stability, strength, endurance and flexibility in students. Particular attention was paid to the formation of skills of independent performance of program exercises at home.

At the third stage of the research, the program provided for changes in the training process and the selection of new exercises in accordance with the individual needs of students.

At the fourth stage the classes were complex and contained two components: the first - the combination of concentric movements with eccentric and neuromotor movements in different planes with and without additional loads, aerobic exercise was directed to strengthen the cardiovascular and respiratory systems; the second component is the performance of physical exercises that take into account the individual needs of students and included the development of muscle groups in certain parts of the body.

At the fifth stage of the research, the morphofunctional condition and physical development of students in the control and experimental groups were assessed. The comparative analysis of the effectiveness of the fitness program "WAY TO A HEALTHY LIFE" was conducted.

\section{Methods}

To obtain the necessary information, we used general scientific research methods, namely: analysis of scientific and methodological sources, pedagogical modelling, pedagogical experiment, pedagogical observation, research methods of functional and physical condition of students, methods pulsometry, theory of motor tests, methods of mathematical statistics.

The analysis of scientific and methodological sources was used to study the current state of views of scientists on the problem of exercise of mature women, determining the requirements for the organization of fitness classes. Pedagogical modelling was used during the development of experimental versions of the content of health fitness classes, which took into account previously obtained information about the functional and physical condition of the subjects [10]. Pedagogical observation was performed to obtain current information about morphofunctional changes and the state of health of students, to determine the impact of exercise on the body of students [11-13]. Methods of studying the functional state of students were used to obtain scientifically sound indicators of the state of the cardiovascular, respiratory and autonomic vegetative nervous system [14-17]. The methods of physical condition research were used to obtain objective indicators of physical development of students at different stages of learning [18-19]. The pedagogical experiment was conducted to determine the effectiveness of the author's fitness program "WAY TO A HEALTHY LIFE" [20]. The methods of mathematical statistics were used to reliably determine the level of development of motor capacities and morphofunctional state of students [21-22]. 
The level of physical health, functionality and physical fitness of students, which we determined at the first, third and fifth stages of the study, is important for the diagnosis of students' physical development. Assessment of the morphofunctional state of students was performed using the express method [23], which involved obtaining results in the following indices:

- Ruffier test (determination of the functional reserve of working capacity of the cardiovascular system);

- Stange test (assessment of the respiratory system with breast holding during inhalation);

- Genchi test (assessment of the respiratory system with breast holding during exhalation);

- Yarotskyi test (assessment of vestibular stability).

- Recovery time after 20 squats (assessment of the recovery processes of the cardiovascular system).

Physical fitness tests were performed at the beginning of the experiment and at the third and fifth stages of the research, using the system of tests that allowed us to assess the functional state of students and determine the level of development of their motor skills. [24-25]. The test system included:

a) running on the spot for 10 seconds (number of steps) speed;

b) squats for 30 seconds (number of performed movements) - leg muscle strength;

c) hyperextension for 30 seconds (number of performed movements) - back muscle strength;

d) twisting the log scale $(\mathrm{cm})$ - flexibility in the shoulder joint;

e) lifting the torso to the buttocks from a supine position behind the head for 30 seconds (number of performed movements) - speed and power abilities; f) maintaining the position of the stop lying on the forearm "plank" (seconds) - strength endurance;

g) balance while standing on one leg with arms outstretched (seconds) - coordination skills.

\section{Results}

The analysis of the dynamics of indicators of morphofunctional state of students of control and experimental groups testifies to the effectiveness of the author's program "WAY TO A HEALTHY LIFE".

The students of the experimental group in comparison with the control group had a process of gradual development of the respiratory system, as indicated by the analysis of the dynamics of the Stange test, which improved in girls from $38.1 \pm 7.8$ to $45.4 \pm 7.5$ (s) (p $<0.001)$; in boys from $42.0 \pm 8.2$ to $51.2 \pm 8.4$ (s) (p $<0.001)$. This fact confirms the analysis of the dynamics of the Genchi test, which gradually improved in students of the experimental group: in girls from $18.7 \pm 5.3$ to 23.3 \pm 4.8 (s) (p <0.01); in boys from $22.8 \pm 5.7$ to $28.2 \pm 6.2$ (s) $(\mathrm{p}<0.01)$. It should be noted that in the students of the control group these, indicators did not undergo significant changes.

The analysis of Ruffier tests showed positive tendency of improving the efficiency of the cardiovascular system in students of the experimental group. During the research, the Ruffier test index changed in girls from the experimental group from $8.54 \pm 1.37$ to $7.92 \pm 1.24$ (unit) ( $\mathrm{p}<0.05$ ), in boys from $8.38 \pm 1.36$ to $7.84 \pm 1.22$ (unit) ( $\mathrm{p}<0.05)$. Recovery time after exercise improved from $64.5 \pm 8.5$ to $56.0 \pm 9.5(\mathrm{~s})(\mathrm{p}<0.01)$ in girls and from 53.5 \pm 9.5 to $46.0 \pm 8.0$ (s) $(\mathrm{p}<0.01)$ in boys, which also confirms the presence of positive changes in the functioning of the cardiovascular and respiratory systems.

Table 1. Dynamics of morphofunctional condition of students at different phases of the experiment $(n=149)$

\begin{tabular}{|c|c|c|c|c|c|c|}
\hline \multirow{2}{*}{} & \multicolumn{3}{|c|}{ Control group of girls (n=38) } & \multicolumn{3}{c|}{ Experimental group of girls (n=40) } \\
\cline { 2 - 7 } & PHASE 1 & PHASE 3 & PHASE 5 & PHASE 1 & PHASE 3 & PHASE 5 \\
\cline { 2 - 7 } & $\mathrm{X} \pm \sigma$ & $\mathrm{X} \pm \sigma$ & $\mathrm{X} \pm \sigma$ & $\mathrm{X} \pm \sigma$ & $\mathrm{X} \pm \sigma$ & $\mathrm{X} \pm \sigma$ \\
\hline Ruffier test (unit) & $8.57 \pm 1.48$ & $8.45 \pm 1.32$ & $8.42 \pm 1.27$ & $8.54 \pm 1.37$ & $8.22 \pm 1.42$ & $7.92 \pm 1.24$ \\
\hline Stange test (s) & $37.7 \pm 7.6$ & $39,4 \pm 9.2$ & $39.2 \pm 8.6$ & $38.1 \pm 7.8$ & $42.5 \pm 8.8$ & $45.4 \pm 7.5$ \\
\hline Genchi test (s) & $17.5 \pm 4.7$ & $18.4 \pm 4.9$ & $18.0 \pm 5.4$ & $18.7 \pm 5.3$ & $20.6 \pm 5.5$ & $23.3 \pm 4.8$ \\
\hline Yarotskyi test (s) & $22.5 \pm 6.2$ & $24.3 \pm 6.5$ & $23.7 \pm 7.2$ & $22.1 \pm 7.9$ & $26.9 \pm 8.3$ & $29.6 \pm 7.5$ \\
\hline Recovery time after 20 squats (s) & $64.0 \pm 14.0$ & $63.5 \pm 13.0$ & $64.0 \pm 12.0$ & $64.5 \pm 8.5$ & $62.5 \pm 8.0$ & $56.0 \pm 9.5$ \\
\hline & \multicolumn{2}{|c|}{ Control group of boys (n=35) } & Experimental group of boys (n=36) \\
\hline Ruffier test & $8.33 \pm 1.27$ & $8.26 \pm 1.34$ & $8.28 \pm 1.41$ & $8.38 \pm 1.36$ & $8.09 \pm 1.28$ & $7.84 \pm 1.22$ \\
\hline Stange test (s) & $42.3 \pm 6.7$ & $44.3 \pm 7.4$ & $45.1 \pm 8.3$ & $42.0 \pm 8.2$ & $46.6 \pm 8.6$ & $51.2 \pm 8.8$ \\
\hline Genchi test (s) & $22.5 \pm 5.5$ & $22.8 \pm 6.2$ & $22.0 \pm 6.7$ & $22.8 \pm 5.7$ & $25.5 \pm 6.2$ & $28.2 \pm 6.4$ \\
\hline Yarotskyi test (s) & $24.5 \pm 5.8$ & $25.2 \pm 6.4$ & $25.5 \pm 6.5$ & $24.8 \pm 5.2$ & $29.8 \pm 7.3$ & $32.7 \pm 5.9$ \\
\hline Recovery time after 20 squats (s) & $54.0 \pm 8.5$ & $52.5 \pm 8,0$ & $53.0 \pm 8.5$ & $53.5 \pm 9.5$ & $48.0 \pm 10.0$ & $46.0 \pm 8.0$ \\
\hline
\end{tabular}


Table 2. Dynamics of indicators of physical development of students at different phases of the experiment $(\mathrm{n}=149)$

\begin{tabular}{|c|c|c|c|c|c|c|c|}
\hline \multirow[t]{2}{*}{ Tests } & \multicolumn{3}{|c|}{ Control group of girls $(\mathrm{n}=38)$} & \multicolumn{3}{|c|}{ Experimental group of girls $(n=40)$} & \multirow[t]{2}{*}{$\begin{array}{l}\text { General } \\
\text { changes }\end{array}$} \\
\hline & PHASE 1 & PHASE 3 & PHASE 5 & PHASE 1 & PHASE 3 & PHASE 5 & \\
\hline & $\mathrm{X} \pm \sigma$ & $\mathrm{X} \pm \sigma$ & $\mathrm{X} \pm \sigma$ & $\mathrm{X} \pm \sigma$ & $\mathrm{X} \pm \sigma$ & $\mathrm{X} \pm \sigma$ & \\
\hline test a (ns) & $30.94 \pm 7.14$ & $31.46 \pm 7.28$ & $31.72 \pm 7.72$ & $31.58 \pm 7.37$ & $34.97 \pm 7.62$ & $37.63 \pm 6.84$ & $+6.05 \pm 0.53$ \\
\hline test $b$ (npm) & $24.16 \pm 5.43$ & $24.57 \pm 5.92$ & $24.68 \pm 5.80$ & $24.41 \pm 5.54$ & $27.14 \pm 6.83$ & $29.27 \pm 6.22$ & $+4.86 \pm 0.68$ \\
\hline test $\mathrm{c}(\mathrm{npm})$ & $20,57 \pm 7.14$ & $20,76 \pm 7.23$ & $20,18 \pm 6.84$ & $20,32 \pm 6.74$ & $21,77 \pm 5.72$ & $23,81 \pm 5.18$ & $+3.49 \pm 1.56$ \\
\hline test $\mathrm{d}(\mathrm{cm})$ & $68.2 \pm 14.2$ & $67.8 \pm 15.4$ & $68.7 \pm 15.1$ & $67.7 \pm 14.2$ & $65.4 \pm 15.8$ & $63.1 \pm 16.3$ & $-4.6 \pm 2.1$ \\
\hline test e (npm) & $17.57 \pm 4.48$ & $18.24 \pm 5.26$ & $17.85 \pm 5.12$ & $17.83 \pm 4.39$ & $19.48 \pm 5.67$ & $20.65 \pm 5.02$ & $+2.82 \pm 0.63$ \\
\hline test $\mathrm{f}(\mathrm{s})$ & $64.8 \pm 22.3$ & $66.1 \pm 20.9$ & $65.2 \pm 24.8$ & $63.4 \pm 23.5$ & $68.1 \pm 25.8$ & $72.7 \pm 24.2$ & $+9.4 \pm 0.7$ \\
\hline \multirow[t]{2}{*}{ test $\mathrm{g}(\mathrm{s})$} & $50.9 \pm 18.8$ & $52.2 \pm 19.6$ & $51.4 \pm 18.4$ & $50.2 \pm 17.7$ & $53.9 \pm 18.2$ & $55.7 \pm 18.6$ & $+5.5 \pm 0.9$ \\
\hline & \multicolumn{3}{|c|}{ Control group of boys $(n=35)$} & \multicolumn{3}{|c|}{ Experimental group of boys $(n=36)$} & \\
\hline test a (ns) & $38.83 \pm 4.49$ & $39.42 \pm 4.77$ & $38.68 \pm 4.93$ & $39.06 \pm 6.16$ & $42.41 \pm 5.79$ & $44.13 \pm 5.43$ & $+5.07 \pm 0.73$ \\
\hline test $b$ (npm) & $24.68 \pm 4.62$ & $24.97 \pm 5.04$ & $24.42 \pm 4.86$ & $24.25 \pm 4.39$ & $27.08 \pm 4.81$ & $28.13 \pm 4.89$ & $+3.88 \pm 0.50$ \\
\hline test c (npm) & $22,82 \pm 6.64$ & $23,16 \pm 7.27$ & $22,68 \pm 6.92$ & $22,54 \pm 6.21$ & $23,91 \pm 6.88$ & $25,71 \pm 6.96$ & $+3.17 \pm 0.75$ \\
\hline test $\mathrm{d}(\mathrm{cm})$ & $81.2 \pm 14.2$ & $80.8 \pm 15.4$ & $81.6 \pm 15.7$ & $80.7 \pm 16.3$ & $78.4 \pm 15.8$ & $77.3 \pm 15.1$ & $-3.4 \pm 1.2$ \\
\hline test e (npm) & $23.12 \pm 3.83$ & $23.55 \pm 4.08$ & $23.35 \pm 3.94$ & $23.47 \pm 3.90$ & $24.58 \pm 4.12$ & $25.84 \pm 4.31$ & $+2.49 \pm 0.41$ \\
\hline test $\mathrm{f}(\mathrm{s})$ & $144.8 \pm 22.3$ & $147.1 \pm 20.9$ & $142.2 \pm 24.8$ & $143.4 \pm 23.2$ & $150.1 \pm 25.8$ & $159.7 \pm 26.5$ & $+16.4 \pm 3.3$ \\
\hline test $\mathrm{g}(\mathrm{s})$ & $50.2 \pm 20.8$ & $51.2 \pm 19.6$ & $51.4 \pm 19.4$ & $48.7 \pm 17.5$ & $50.6 \pm 16.2$ & $53.2 \pm 15.3$ & $+4.5 \pm 2.2$ \\
\hline
\end{tabular}

The developed program "WAY TO A HEALTHY LIFE" helped to improve the vestibular stability of students, which provides stability in the performance of techniques and exercises. Analysis of Yarotskyi test shows the improvement of vestibular stability in students of the experimental group from $22.1 \pm 7.9$ to $29.6 \pm 7.5$ (s) $(\mathrm{p}<0.001)$ in girls and from $24.8 \pm 5.2$ to $32.7 \pm 5.9$ (s) (p $<0.001)$ in boys. These indicators did not undergo significant changes of the students of the control group.

We found out that the indicators of physical development of students in the control group, engaged in the constant training program, did not change significantly and was within the statistical error.

The developed program "WAY TO A HEALTHY LIFE" promoted the development of speed, leg muscle strength, back muscle strength, flexibility in the shoulder joint, strength endurance and improved speed, strength and coordination skills. Analysis of the dynamics of indicators of physical development of students in the experimental group showed significantly positive changes in the following exercises: running on the spot for 10 seconds (speed) $+6.05 \pm 0.53(\mathrm{~ns})(\mathrm{p}<0.001)$ in girls, + $5.07 \pm 0.73(\mathrm{~ns})(\mathrm{p}<0.001)$ in boys; squats for 30 seconds (leg muscle strength) $+4.86 \pm 0.68(\mathrm{npm})(\mathrm{p}<0.01))$ in girls, $+3.88 \pm 0.50(\mathrm{npm})(\mathrm{p}<0.01)$ in boys; hyperextension for 30 seconds (back muscle strength) + $3.49 \pm 1.56(\mathrm{npm})(\mathrm{p}<0.01)$ in girls, $+3.17 \pm 0.75(\mathrm{npm})$ ( $\mathrm{p}<0.01)$ in boys; twisting the log scale (flexibility in the shoulder joint $)-4.6 \pm 2.1(\mathrm{~cm})(\mathrm{p}<0.05)$ in girls, $-3.4 \pm$ $1.2(\mathrm{~cm})(\mathrm{p}<0.05)$ in boys; lifting the torso to the side from a supine position with the hands behind the head for
30 seconds (speed and power abilities) $+2.82 \pm 0.63(\mathrm{npm})$ $(\mathrm{p}<0.05)$ in girls, $+2.49 \pm 0.41(\mathrm{npm})(\mathrm{p}<0.05)$ in boys; maintaining the position of the stop lying on the forearm "plank" (strength endurance) $+9.4 \pm 0.7(\mathrm{~s})(\mathrm{p}<0,01)$ in girls, $+16.4 \pm 3.3(\mathrm{~s})(\mathrm{p}<0,01)$ in boys; maintaining balance while standing on one leg with arms outstretched (coordination abilities) $+5.5 \pm 0.9(\mathrm{~s})(\mathrm{p}<0.05)$ in girls, + $4.5 \pm 2.2(\mathrm{~s})(\mathrm{p}<0.05)$ in boys.

\section{Discussion}

The characteristic difference of the developed author's fitness program "WAY TO A HEALTHY LIFE" was the inclusion of three components into its content: "SUPER ABDOMINAL MUSCLES, SLIM LEGS AND PERFECT BUTTOCK"; "STRONG FLEXIBLE BODY"; "STRONG HANDS, ELASTIC CHEST AND STRONG BACK". They are logically interconnected and complementary. The special feature of physical education classes was the use of online platforms ZOOM, Google Meet, Viber, Telegram, as the element of feedback between a student and a teacher, providing the necessary methodological assistance and monitoring the implementation of physical exercises. The practical test of the theoretical provisions of the author's program "WAY TO A HEALTHY LIFE" was conducted.

The research was based on the views of the modern scientists who have considered the problem of organizing fitness training of students in the following areas: analysis of modern approaches to the organization and conduct of 
physical education classes [26-27]; research of indicators of physical health of students at different stages of training [12], [22], [31]; study of morphofunctional indicators of physical development of students in the conditions of restrictions of motor activity caused by pandemic COVID-19 [28-29]; introduction of various fitness programs into the educational process [6], [21], [25]; conducting of the comparative analysis of curricula in physical education [30-31]; introduction of the most effective and popular among young people modern sports activities, taking into account various restrictions [20], [33-34]; conducting physical education classes based on value-oriented learning [35-37]; taking into account current tendencies in the development of physical education and timely changes in the training of specialists in the sphere of physical culture and sports [38-39].

Analysis of the obtained results of our research confirms the research [2], [12], [21], [26] on the priority of improving health and personal attractiveness in the value system of young people during fitness. The research data [7], [15], [19], [33] on the introduction of various fitness systems as a health and correctional type of physical training of students, establishing its positive impact on the level of physical health of the subjects has been expanded. The results of our research confirm the researches [11], [13], [20], [25] on the effectiveness of the combined training on improving the functionality and development of the muscular system of students, the correction of their body shape.

According to the results of our research, the data on the practical application of the method of conducting classes on the complex combination of various modern fitness technologies were extended, namely: shaping, bodyflex, Pilates, and stretching [5], [6], [22]. The conducted research confirmed and expanded the scientific views of scientists [7], [8], [21], [24] on the need for systematic assessment of physical health, functional status and physical fitness of students at each stage of the sstudy, which allows for timely changes and make adjustments in the organization of fitness classes.

\section{Conclusions}

1. The use of the author's program "WAY TO A HEALTHY LIFE" allowed to make classes flexible and varied, to take an individual approach to each student, which helped to increase their physical fitness and efficiency, improve the functional state of the body, physical health and psycho-emotional state.

2. Analysis of the dynamics of indicators of morphofunctional state of students of the experimental group in comparison with the control group shows positive impact of the author's program "WAY TO A HEALTHY LIFE". The students of the experimental group improved the functional indicators of the development of the cardiovascular, respiratory systems and vestibular stability. The increase was: in the Stange test $+7.3 \pm 0.5(\mathrm{~s})(\mathrm{p}<0.001)$ in girls, +9.2 $\pm 0.4(\mathrm{~s})(\mathrm{p}<0.001)$ in boys; Genchi tests $+4.6 \pm 0.5$ (s) $(\mathrm{p}<0.01)$ in girls, $+5.4 \pm 0.7(\mathrm{~s})(\mathrm{p}<0.01)$ in boys; Yarotskyi tests $+7.5 \pm 0.4(\mathrm{~s})(\mathrm{p}<0.001)$ in girls,+7.9 \pm 0.7 (s) (p <0.001) in boys; recovery time after exercise improved $-8.5 \pm 2.5$ (s) $(\mathrm{p}<0.01)$ in girls and $-7.5 \pm 1.5(\mathrm{~s})(\mathrm{p}<0.01)$ in boys.

3. Analysis of the physical condition of students at the beginning and at the end of the experiment shows that the students of the experimental group in comparison with the control group had significant changes in speed $+6.05 \pm 0.53(\mathrm{~ns})(\mathrm{p}<0.001)$ in girls, $+5.07 \pm$ 0.73 (ns) (p <0.001) in boys; leg muscle strength + $4.86 \pm 0.68(\mathrm{npm})(\mathrm{p}<0.01)$ in girls, $+3.88 \pm 0.50$ $(\mathrm{npm})(\mathrm{p}<0.01)$ in boys; back muscle strength $+3.49 \pm$ $1.56(\mathrm{npm})(\mathrm{p}<0.01)$ in girls, $+3.17 \pm 0.75(\mathrm{npm})(\mathrm{p}$ $<0.01)$ in boys; flexibility in the shoulder joint $-4.6 \pm$ $2.1(\mathrm{~cm})(\mathrm{p}<0.05)$ in girls, $-3.4 \pm 1.2(\mathrm{~cm})(\mathrm{p}<0.05)$ in boys; improvement of speed and power abilities +2.82 $\pm 0.63(\mathrm{npm})(\mathrm{p}<0.05)$ in girls, $+2.49 \pm 0.41(\mathrm{npm})(\mathrm{p}$ $<0.05)$ in boys; improvement of strength endurance + $9.4 \pm 0.7(\mathrm{~s})(\mathrm{p}<0.01)$ in girls, $+16.4 \pm 3.3(\mathrm{~s})(\mathrm{p}<0.01)$ in boys; improvement of coordination abilities $+5.5 \pm$ $0.9(\mathrm{~s})(\mathrm{p}<0.05)$ in girls, $+4.5 \pm 2.2(\mathrm{~s})(\mathrm{p}<0.05)$ in boys.

\section{Conflicts of Interest}

No conflicts of interest exist.

\section{Ethical Approval}

All procedures performed in studies involving human participants were in accordance with the ethical standards of the institutional and/or national research committee and with the 1964 Helsinki declaration and its later amendments or comparable ethical standards.

\section{Informed Consent}

Informed Consent Informed consent was obtained from all individual participants included in the study. All subjects of the institutional survey gave consent for anonymised data to be used for publication purposes.

\section{REFERENCES}

[1] S.M. Futornyi, "The problem of lack of physical activity of student youth". Physical education of students. Kharkiv, Vol. 3, pp. 75-79, 2013. 
[2] N.V. Trietiakova, T.V. Andriukhina, Ye.V. Ketrish, "Theory and methods of health-improving physical culture": textbook. Moscow: Sport, 2016.

[3] O. Mozolev, O. Polishchuk, L. Kravchuk, O. Tatarin, O. Zharovska, V. Kazymir, "Results of monitoring the physical health of female students during the COVID-19 pandemic". Journal of Physical Education and Sport, Vol. 20 Issue 6, pp. $3280-3287, \quad 2020$, DOI:10.7752/jpes.2020.s6445.

[4] I.V. Krivientsova, V.G. Klimenchenko, O.V. Ivanov, "Distance education in physical education during quarantine". Physical Rehabilitation and Recreational Health Technologies, Vol. 5 (2). pp. 98-103, 2020.

[5] Yu.A. Usachev, "Physical culture and health technologies for the formation of fitness culture of students": textbook. Kiev: Logos, 2014.

[6] O. Mozolev, I. Bloshchynskyi, O. Alieksieiev, L. Romanyshyna, L. Zdanevych, I. Melnychuk, K. Prontenko, \& V. Prontenko, "Influence of modern fitness technologies on the state of health and development of motor abilities of 17-19-year-old female students". Journal of Physical Education and Sport, Vol. 19 (3), pp. 917 - 924, 2019, doi: 10.7752 / jpes.2019.s3132.

[7] O. Mozolev, I. Bloshchynskyi, K. Prontenko, L. Zdanevych, K. Kruty, O. Popovych, L. Pisotska, "Influence of fitness techniques integration on the development of physical qualities and morpho-functional state of adult females". Hum Mov.; Vol. 22 (1), pp. 55-63, 2021, doi: 10.5114/hm.2021.98465.

[8] L. Vashchuk, "Algorithm for building individual fitness programs for independent classes". Physical Education, Sport, and Health Culture in Modern Society., Vol. 2 (34), pp. 20-35, 2016.

[9] Edward T. Hawley, "Health Fitness Instructor's Guide". Kiev: Publishing House "Olympic Literature”, 2004.

[10] O. Mozolev, "Pedagogical Projecting of the Model of a Future Specialist". Pedagogical Discourse, Vol. 24, pp. 8287, 2018, DOI: 10.31475/ped.dys.2018.24.12.

[11] L. A. Chekhovska. "Health fitness in modern society". Lviv: LDUFK, 2019.

[12] V.M. Vilianskyi, "Building your own health: from philosophy to practice". Teaching manual. Dnipropetrovsk: National Mining University, 2011.

[13] O.V. Shumakov, "The role of independence in modern health technologies of physical education of students". Pedagogy, psychology and medical-biological problems of physical education and sports. Vol. 7, pp. 115-118, 2010.

[14] I.I. Zemtsova, "Sports physiology". Kyiv: Olympic Literature, 2008.

[15] H. L. Apanasenko, "Individual Health: Theory and Practice. Introduction to the Theory of Individual Health" Kiev-Medkniga. 2011.

[16] R.B. Burke. "Precision Heart Rate Training". Champaign: Human Kinetics, 1998.

[17] J.Jr. Morrow, A. Jackson, J. Disch, D. Mood.
"Measurement and Evaluation in Human Performance". Champaign: Human Kinetics, 2008.

[18] O. Z. Blavt "Informative Indices of the Level of Physical Health and Physical Fitness of University Students". Pedagogy, Psychology and Medical-Biological Problems of Physical Education and Sports, Vol. 11, pp. 14-18, 2012.

[19] O. Mozolev, L. Kravchuk, N. Ostrovska, O. Nahorna, O. Polishchuk, \& M. Khmara, "Checking the effectiveness of the method of conducting physical education classes with 17-19 -year-old female students of special medical group". Journal of Physical Education and Sport, Vol. 20 Issue 2, pp. 870 - 876, 2020, DOI:10.7752/jpes.2020.02124.

[20] V. Zhamardiy, O. Shkola, I. Okhrimenko, O. Strelchenko, A. Aloshyna, F. Opanasiuk, G. Griban, V. Yahodzinskyi, O. Mozolev, K. Prontenko, "Checking of the methodical system efficiency of fitness technologies application in students' physical education". Wiadomości Lekarskie, Vol.73 (2), pp. 332 - 341, 2020, Doi: 10.36740/WLek202002125.

[21] B. Sharkey, S. Gaskill, "Fitness \& health. Human Kinetics", 2013.

[22] G. Griban, O. Skoruy, K. Pantielieiev, Y. Brytan, et al. "Influence of Physical Education Classes on the Level of Health and Fitness Competencies of Students". International Journal of Applied Exercise Physiology, Vol. 9 (12) pp. $107 \quad-\quad 118, \quad 2020$, Doi: 10.26655/IJAEP.2020.12.1.

[23] V.V. Chyzhyk., O.K. Dudnyk, "Research methods in physical education": textbook. Bila Tserkva: 2013.

[24] V.M. Serhiienko, "Control and assessment of motor abilities of students in the process of physical education". Sumy: SDU, 2014.

[25] P. Gallo, "Health Fitness Professional, Group Exercise Instructor, and Clinical Exercise Physiologist Walk into a Fitness Facility". ACSM's Health \& Fitness Journal. Vol. 24 (2), pp. 40-42, 2020.

[26] O. K. Kornosenko, "The role of fitness in the system of health physical culture". Bulletin of Chernihiv National Pedagogical University named after T.H. Shevchenko. Vol. 112 (3), pp. 228-232, 2013.

[27] N.Yu. Dovgan, (2016). "Modern approaches to formation of physical culture of students in higher education system". Fundamental and Applied Researches In Practice of Leading Scientific Schools, 4(16), 61-80, 2016.

[28] G. Griban, O. Kobernyk, N. Terentieva, O. Shkola, Z. Dikhtiarenko, et al. "Formation of Health and Fitness Competencies of Students in the Process of Physical Education". Sport Mont 18(3): pp.73-78, 2020, DOI 10.26773/smj.201008

[29] Oleksandr Mozolev, Oleksandr Polishchuk, Inna Shorobura, Valentina Miroshnichenko, Klavdiia Tushko, Volodymyr Voloshyn, Ihor Tomkiv, Oleksandr Binkovskyi , "Motor Activity and Physical Abilities of Students in the Conditions of Restrictions of COVID-19," International Journal of Human Movement and Sports Sciences, Vol. 9, No. 3, pp. 428 - 435, 2021. DOI: 10.13189/saj.2021.090306. 
[30] S. Hambali, A. Akbaruddin, D. Bustomi, A. Rifai, T. Iskandar, A. Ridlo, Y. Meirizal, R. Rusmana, R. Tyas. The Effectiveness Learning of Physical Education on Pandemic COVID-19. International Journal of Human Movement and Sports Sciences. Vol. 9 (2), pp. 219 - 223, 2021, DOI: 10.13189/saj.2021.090208.

[31] I.M. Melnychuk, S.O. Yastremska, D.V. Popovych, V.V. Humeniuk, O.V. Yefremova, L.V. Novakova, O.V. Shukatka, "Health Dynamics of the Medical University Students During Sports Activities". Wiadomości Lekarskie; Vol.74(2), pp. 295-302, 2021 DOI:10.36740/WLek202102123

[32] O. Mozolev, \& M. Khmara. "Comparative Analysis of the Effectiveness of the Polish and Ukrainian Basic Training Programs for Physical Education of Primary School Students". Pedagogical Discourse, 27, 7-17, 2019, doi: 10.31475/ped.dys.2019.27.01

[33] O. Mozolev, M. Khmara, I. Shorobura, I. Bloshchynskyi, K. Prontenko, O. Polishchuk, L. Zdanevych, K. Kruty. "Comparative Analysis of the Effectiveness of Polish and Ukrainian Basic Training Programs in Physical Education for 9-10-year-old Pupils". Universal Journal of Educational Research 7(11): 2345-2351, 2019, DOI: 10.13189/ujer.2019.071112.

[34] V. Kashuba, M. Kolos, O. Rudnytskyi, V. Yaremenko, V. Shandrygos, M. Dudko, O. Andrieieva, "Modern approaches to improving body constitution of female students within physical education classes". Journal of physical education and sport. 17(4):2472-2478, 2017. DOI: 10.7752/jpes.2017.04277.
[35] A. I. Ilchenko, "Formation of value attitude to health and developmental motor activity". Theoretical and methodological problems of education of children and students, Vol 18 (1). pp. 280-288, 2014.

[36] O. Mozolev, M. Khmara, I. Yashchuk, L. Kravchuk, V. Matviichuk, A. Kalenskyi, V. Miroshnichenko, O. Halus, "The Influence of Value-oriented Teaching upon Vital Competences Formation of 7-9 Years Old Pupils during Physical Education Lessons". Universal Journal of Educational Research 8(6): 2352-2358, 2020, DOI: 10.13189/ujer.2020.080619

[37] K. Prontenko, G. Griban, A. Aloshyna, S. Bezpalyi, T Yavorska, S. Hryshchuk, P. Tkachenko, D. Dzenzeliuk, I. Bloshchynskyi. "The physical development and functional state as the important components of the students' health", Wiadomości Lekarskie, Vol.72 No.12, part 1, pp. 2348-2353, 2019. doi: 10.36740/WLek201912115

[38] O. Soltyk Y. Pavlyuk, B. Vynogradskyi, O. Pavlyuk, T. Chopyk, O. Antoniuk, "Improvement of professional competence of future specialists in physical education and sports during the process of vocational training". Journal of Physical Education and Sport, Vol. 17 (3), pp. 964-969, 2017, doi:10.7752/jpes.2017.s3148.

[39] O. Mozolev, O. Halus, I. Bloshchynskyi, \& R. Kovalchuk, "Human resources management of educational development in sphere of physical culture and sports in Ukraine: comparative analysis (1992-2016)". Journal of Physical Education and Sport, Vol. 19 (1), Art 28, pp. 185-192, 2019, doi:10.7752/jpes.2019.s1028. 